Sociedade, Contabilidade e Gestão, Rio de Janeiro, v. 5, n. Especial, 2010.

\title{
Controles Internos em Pequenas Comunidades Católicas de Florianópolis
}

\author{
Laura Letsch Soares \\ Mestranda em Ciências Contábeis - UFSC \\ Campus Universitário - Trindade - Florianopolis - SC - Caixa-Postal 476 - 88040-900 \\ lauraletsch@hotmail.com
}

Ernesto Fernando Rodrigues Vicente

Doutor em Administração - FEA/USP

Professor do Programa de Pós-Graduação em Ciências Contábeis da UFSC

Departamento de Ciências Contábeis - Campus Universitário - Trindade - Florianopolis - SC

- Caixa-Postal 476 - 88040-900

e.fernando@cse.ufsc.br

Rogério João Lunkes

Doutor em Engenharia de Produção - UFSC

Professor do Programa de Pós-Graduação em Ciências Contábeis da UFSC

Departamento de Ciências Contábeis - Campus Universitário - Trindade - Florianopolis - SC

- Caixa-Postal 476 - 88040-900

lunkes@cse.ufsc.br

\section{Resumo}

O Brasil é um dos países com maior número de católicos do mundo. Em contrapartida, observa-se o surgimento e crescimento de novas religiões. A população busca os serviços oferecidos pelas entidades religiosas e se dispõe a contribuir financeiramente para a manutenção de seus templos. O Brasil é um Estado que concede a liberdade de crença, assegura o livre exercício dos cultos religiosos e garante proteção aos locais de culto e a suas liturgias. Entretanto, por ser um estado laico, não pode apoiar nenhuma religião especificamente, sendo vedada, constitucionalmente, a manutenção de relações de dependência ou de alianças. $\mathrm{O}$ custeio da promoção das entidades religiosas cabe aos seus seguidores. Os recentes escândalos de corrupção ligados a entidades religiosas de vários credos, referentes a recursos não declarados e desvio de recursos doados por fiéis, motivaram a realização deste trabalho junto a pequenas comunidades católicas para verificar a existência de procedimentos de controles internos que assegurem a salvaguarda dos ativos confiados a essas entidades e verificar se eles oferecem aos fiéis transparência quanto à aplicação dos recursos recebidos em doação. $\mathrm{O}$ trabalho foi desenvolvido nas comunidades vinculadas a uma paróquia do município de Florianópolis, mediante a aplicação de questionário para levantamento de dados. Os resultados alcançados foram a identificação do perfil das equipes responsáveis pelo gerenciamento dos recursos financeiros, a identificação dos procedimentos contábeis e de controle interno adotados e a identificação de fragilidades, concluindo que, apesar da existência de falhas, as comunidades adotam procedimentos de controle interno adequados.

Palavras-chave: Controles Internos em Igrejas. Contabilidade Eclesiástica. Contabilidade em Entidades Sem Fins Lucrativos.

Artigo publicado anteriormente nos Anais do I AdCont em 2010.

Artigo submetido em 26 de novembro de 2010 e aceito em 10 de dezembro de 2010 pelo Editor Marcelo Alvaro da Silva Macedo, após double blind review. 


\begin{abstract}
Brazil is a country with largest number of Catholics in the world. In contrast, we observe the emergence and growth of new religions. The people search services offered by religious organizations and is willing to contribute financially to the maintenance of their temples. Brazil is a country that grants freedom of belief, it ensures the free exercise of religious worship and ensures protection of places of worship and their liturgies. However, being a secular country cannot support any religion specifically, being forbidden, constitutionally, maintenance of dependency relations or alliances. The cost of the promotion of religious organizations rests with their followers. The recent corruption scandals linked to religious organizations of various faiths, referring to not declared resources and misuse of funds donated by believers, motivated this work with the small Catholic communities to verify the existence of internal control procedures to ensure the safeguarding of assets entrusted to these organizations and see if they offer true transparency on the use of funds received as donations. The study was conducted in communities linked to a parish in the municipality of Florianópolis, by applying a questionnaire to collect data. The results were the profile identification of the staff responsible for managing financial resources, the identification of accounting and internal control adopted and the identification of weaknesses, concluding that despite the existence of failures, the communities adopt adequate internal control procedures.
\end{abstract}

Keywords: Internal Controls on Churches. Ecclesiastical Accounting. Accounting in Nonprofits Organizations.

\title{
1 - Introdução
}

O fato de o Brasil ser um dos países com maior número de católicos no mundo, aliado ao surgimento de novas religiões, torna evidente que a população busca os serviços de apoio espiritual oferecidos por entidades religiosas e que o povo está disposto a contribuir para a manutenção dos templos e de suas atividades assistenciais. Os recursos são doados de boa-fé, amparados no intuito particular de cada fiel em praticar o bem e repartir um percentual de seus ganhos com os mais necessitados, bem como manter os templos e a estrutura eclesiástica.

Os recentes escândalos veiculados na imprensa referentes às Igrejas Renascer em Cristo e Universal, envolvendo não declaração de recursos levados em espécie para os Estados Unidos pela primeira e desvio de recursos doados pelos fiéis para patrimônio particular dos dirigentes, aquisição de empresas e depósitos bancários no exterior, pela segunda, evidenciam que há possibilidade da ocorrência de desvios de finalidade dos recursos doados. Corroborando, West (2008) relata o emprego indevido de recursos, doados à Igreja Católica Americana, em favor de religiosos a fim de defendê-los de denúncias por desvios sexuais.

A adoção de práticas de controles internos deve ser levada a efeito em instituições religiosas para estabelecer mecanismos que assegurem aos fiéis que os recursos doados estão tendo a correta aplicação e inibir práticas de corrupção.

Este estudo visa verificar quais os mecanismos de controle contábil e/ou de controladoria são adotados pelas equipes econômicas das comunidades da Igreja Católica de Florianópolis sobre as receitas auferidas e a execução das despesas. 


\section{2 - Referencial Teórico}

Este estudo abrange várias áreas do conhecimento, predominando as de contabilidade eclesiástica e de controle interno nas organizações.

\section{1 - Contabilidade Eclesiástica}

A Constituição Federal de 1988 assegurou a liberdade de crença como um dos Direitos e Garantias Individuais. O art. 5, nos incisos VI e VII, expressa que "é inviolável a liberdade de consciência e de crença, sendo assegurado o livre exercício dos cultos religiosos e garantida, na forma da lei, a proteção aos locais de culto e a suas liturgias" e "é assegurada, nos termos da lei, a prestação de assistência religiosa nas entidades civis e militares de internação coletiva". A Constituição também concedeu imunidade tributária às instituições religiosas. $\mathrm{O}$ art. 150 pró́be a instituição de tributos sobre templos de qualquer culto, por qualquer esfera de governo. Como o Brasil é um Estado laico, sem interferência religiosa na condução dos assuntos do governo, o art. 19 impediu a União, os Estados, o Distrito Federal e os Municípios de estabelecer cultos religiosos ou igrejas, subvencioná-los, embaraçar-lhes o funcionamento ou manter com eles ou seus representantes relações de dependência ou aliança, ressalvados os casos de colaboração de interesse público previstos em lei.

O novo Código Civil estabelece que as organizações religiosas são pessoas jurídicas de direito privado, juntamente com as associações, as sociedades, as fundações e os partidos políticos. Portanto, apesar das prerrogativas previstas na Constituição Federal, as Igrejas e as Organizações Religiosas estão submetidas ao ordenamento jurídico vigente, sujeitas, no âmbito da sociedade civil organizada, a várias questões legais, tais como trabalhistas, previdenciárias, administrativas, imobiliárias, financeiras, tributárias, fiscais, criminais, responsabilidade civil por danos causados a terceiros, entre outras. Paralelamente à discussão sobre o novo Código Civil, Duarte (2002, p. 24) afirma que "a igreja tornou-se uma corporação que despertou o interesse investigativo da grande imprensa e do administrador público no seu contexto externo ou visível" (apud França, 2007, p 16).

A partir da década de 90, o denominado Terceiro Setor entrou em evidência no Brasil. No âmbito do Conselho Federal de Contabilidade foi emitida a NBC T 10.19, referente às entidades sem finalidade de lucros, que se destina a orientar o atendimento às exigências legais sobre procedimentos contábeis a serem atendidos pelas pessoas jurídicas de direito privado sem finalidade de lucro, abrangendo, portanto, as instituições religiosas de qualquer credo. Oliveira (2002 p 74) registra que o terceiro setor, na América Latina, é responsável por grande parte dos projetos institucionais de auxílio a grupos sociais marginalizados, organização comunitária e defesa dos direitos civis e que as organizações religiosas continuam exercendo um papel de destaque.

Em 2006 a arquidiocese de Florianópolis reeditou o Regimento Interno dos Conselhos e Assembléias de Pastoral que estabelece as regras para composição e funcionamento das diversas instâncias de representação e administração pastoral no âmbito da sua jurisdição.

\section{2 - Controle Interno}

"A religião pode ser estudada de diversos ângulos e a partir de diferentes ramos do conhecimento" França (2007, p 16). Do ponto de vista administrativo essas organizações, assim como qualquer outra, necessitam de boa gestão para administrar seus recursos e manter patrimônio.

Crepaldi (1998) enumera os seguintes objetivos dos controles internos de uma entidade: 
- Salvaguardar os ativos;

- Verificar a exatidão e fidedignidade dos dados e relatórios;

- Trazer maior eficiência para as operações; $e$

- Comunicar e estimular o cumprimento das políticas, normas e procedimentos administrativos adotados.

Lunkes e Schnorrenberger (2009) explicam que os controles internos podem ser segregados em três grandes categorias: organizacionais e estruturais, avaliação de riscos e sistemas de informações e de métodos e procedimentos. A figura 1 demonstra esquematicamente a composição dessas três categorias.

\begin{tabular}{|c|c|c|}
\hline \multicolumn{3}{|c|}{ CONTROLES INTERNOS } \\
\hline Organizacionais e estruturais & $\begin{array}{c}\text { Avaliação de riscos e sistemas de } \\
\text { informações }\end{array}$ & Métodos e procedimentos \\
\hline $\begin{array}{ll}\text { - } & \text { Comportamentais } \\
\text { - } & \text { Treinamento } \\
\text { - } & \text { Segregar responsabilidades } \\
\text { - } & \text { Estabelecer níveis de autorização } \\
\text { - } & \text { Controles físicos } \\
\text { - } & \text { Auditoria internas }\end{array}$ & $\begin{array}{ll}\text { - } & \text { Registro completo e preciso } \\
\text { - } & \text { Base de dados segura } \\
\text { - } & \text { Relatórios gerenciais oportunos } \\
\text { - } & \text { Fatores externos }\end{array}$ & $\begin{array}{ll}\text { - } & \text { Regulamentos } \\
\text { - } & \text { Manuais } \\
\text { - } & \text { Rotinas de trabalho }\end{array}$ \\
\hline
\end{tabular}

Figura 1 - Quadro sinótico dos elementos de controles internos

Fonte: Lunkes e Schnorrenberger (2009)

Os motivos para a implementação de controle internos em uma entidade são inúmeros. Lunkes e Schnorrenberger (2009) afirmam que o sistema de controle interno "é o ingrediente fundamental para prevenir perdas de toda ordem, inclusive as decorrentes de fraudes". Além disso, eles contribuem para melhorar a tomada de decisões. Os autores afirmam que as fraudes e os desperdícios são preocupações constantes dos gestores e os sistemas de controles internos devem ser projetados para minimizá-los e lembram que mesmo em organizações de pequeno porte as questões relativas a controles internos devem ser consideradas, pois as instituições menores são tão ou mais suscetíveis a fraudes quanto as grandes.

Este trabalho insere-se no contexto de entidades de pequeno porte, uma vez que cada Capela tem autonomia para promover a arrecadação de seus recursos e decidir sobre sua aplicação, agindo em consonância com o Regimento Interno dos Conselhos e Assembléias de Pastoral.

Em que pese o berço da contabilidade científica ter sido o meio religioso, com a publicação do "Método das Partidas Dobradas" pelo Frei Lucca Paccioli, observa-se que há pouco material teórico publicado sobre contabilidade eclesiática. Em publicações internacionais encontram-se vários artigos envolvendo o assunto. Contudo, no Brasil não foi evidenciada a publicação de artigos em periódicos e congressos técnicos ou acadêmicos. Alves, Olak e Slomsky (2008, p 33) pesquisaram a produção acadêmica da área contábil voltadas para o terceiro setor, onde se inserem as instituições religiosas, abrangendo as teses e dissertações defendidas registradas na Coordenação de Aperfeiçoamento de Pessoal de Nível Superior (Capes), os Anais do Encontro da Associação Nacional de Pós-Graduação e Pesquisa em Administração (Enanpad) e o Congresso Usp de Controladoria. Eles evidenciaram que não há, nestas bases de dados, "produção científica expressiva na área contábil antes de 2000. No período de 2000 a 2006, os autores, pesquisaram, além das bases citadas, a produção acadêmica publicada na Revista Contabilidade e Finanças (USP) e na Revista Brasileira de Contabilidade (CFC) e concluem que "a produção acadêmica contábil na área do Terceiro Setor é muito incipiente no Brasil” Alves, Olak e Slomsky (2008, p 38). 
Observa-se a publicação de estudos a respeito de controles internos em entidades religiosas em outros países como Austrália, Malásia, Inglaterra e Estados Unidos. No Brasil não se verifica a produção e publicação de estudos acadêmicos nesta área.

West (2008) relaciona estudos acerca da inadequação de controles internos em igrejas em vários países:

Tem havido um grande número de estudos que têm demonstrado a importância e a inadequação geral dos controles financeiros internos em igrejas (Chester, et al, 1999; Duncan, et al, 1999; Edwards, 1990; Flesher e Duncan, 1999; Harper e Harper, 1988; Jordan, et al 1991; McEldowney, et al, 1993; Smith e Miller, 1989; e Stock, 1995). Outros se têm centrado na relação entre os aspectos espirituais de uma igreja e as suas práticas contábeis (Abdul-Rahman e Goddard, 1998; Booth, 1993; e Loughlin, 1998).

\section{3 - Metodologia de Pesquisa}

\section{1 - Informações Gerais}

O objetivo do trabalho é levantar quais os procedimentos de controle interno que se relacionam ao recebimento da renda e sua aplicação e demais procedimentos adotados para a salvaguarda dos ativos da comunidade. Este estudo tem caráter descritivo, seguido de análise qualitativa e quantitativa.

A pesquisa foi realizada através da estratégia 'survey', ou seja, levantamento de dados com propósito descritivo, caracterizando um estudo de caso que, segundo Yin (2001), é um método que contribui para a compreensão de fenômenos individuais, organizacionais, sociais e políticos. Esse método geralmente é escolhido quando os investigadores não têm controle sobre os eventos e devido ao foco temporal, por tratarem-se de acontecimentos contemporâneos. Anteriormente, Gil (1997) afirmou que o estudo de caso pode utilizar a observação direta como forma de coleta de dados para este tipo de estudo, pois o assunto focado por este trabalho, nesse tipo de entidade, é ainda pouco explorado.

Primeiramente foi realizado estudo bibliográfico a fim de identificar os livros e artigos publicados sobre o assunto. A pesquisa foi iniciada no Portal de Periódicos da Capes de acesso livre para Textos Completos, em todos os idiomas, no Assunto de Ciências Sociais Aplicadas. Através da expressão "controle interno igrejas" identificaram-se os artigos publicados sobre o assunto em periódicos nacionais. Tomou-se por base o artigo elaborado por Sulaiman (2007) a respeito das Mesquitas da Malásia publicado pelo periódico Universo Contábil. Adaptou-se os questionários utilizados por Sulaiman para a captação de informações sobre as comunidades católicas em Florianópolis. Através das referências bibliográficas foram analisados outros artigos relacionados ao assunto.

O procedimento metodológico utilizado foi o de coleta, sistematização e análise de dados. Para o levantamento dos dados foram utilizadas fontes primárias através de questionários. As fontes secundárias foram artigos em publicações especializadas, levantados na pesquisa bibliográfica e em sites da internet.

A coleta de dados foi realizada, no segundo semestre do ano de 2009, nas comunidades ligadas a uma paróquia da arquidiocese de Florianópolis, mediante aplicação de questionários preenchidos pela Equipe Econômica de cada comunidade-membro.

Os municípios que pertencem à arquidiocese de Florianópolis e seus habitantes estão demonstrados na Tabela 1.

No município de Florianópolis, onde foi realizado o estudo, estão constituídas dezoito Paróquias, conforme a Tabela 2. 
Tabela 1 - Municípios abrangidos pela arquidiocese de Florianópolis

\begin{tabular}{|l|l|}
\hline Águas Mornas (4.520 habitantes) & Itajaí (169.927 habitantes) \\
\hline Angelina (5.436 habitantes) & Itapema (35.655 habitantes) \\
\hline Anitápolis (3.266 habitantes) & Leoberto Leal (3.683 habitantes) \\
\hline Antônio Carlos (7.375 habitantes) & Major Gercino (2.897 habitantes) \\
\hline Balneário Camboriú (99.493 habitantes) & Nova Trento (11.832 habitantes) \\
\hline Biguaçu (55.665 habitantes) & Palhoça (128.360 habitantes) \\
\hline Bombinhas (13.241 habitantes) & Paulo Lopes (7.198 habitantes) \\
\hline Botuverá (4.294 habitantes) & Porto Belo (13.910 habitantes) \\
\hline Brusque (99.917 habitantes) & Rancho Queimado (2.871 habitantes) \\
\hline Camboriú (56.315 habitantes) & Santo Amaro da Imperatriz (18.266 habitantes) \\
\hline Canelinha (10.068 habitantes) & São Bonifácio (3.271 habitantes) \\
\hline Florianópolis (402.346 habitantes) & São João Batista (23.547 habitantes) \\
\hline Garopaba (16.577 habitantes) & São José (199.280 habitantes) \\
\hline $\begin{array}{l}\text { Governador Celso Ramos (12.611 } \\
\text { habitantes) }\end{array}$ & São Pedro de Alcântara (5.038 habitantes) \\
\hline Guabiruba (16.925 habitantes) & Tijucas (29.122 habitantes). \\
\hline
\end{tabular}

Fonte: Arquidiocese de Florianópolis - www.arquifln.org.br

Tabela 2 - Paróquias do município de Florianópolis

\begin{tabular}{|c|l|l|}
\hline Ordem & Bairro & Nome da paróquia \\
\hline 1 & Agronômica & Nossa Senhora de Lourdes e São Luiz \\
\hline 2 & Balneário & Nossa Senhora da Glória \\
\hline 3 & Canasvieiras & Nossa Senhora de Guadalupe \\
\hline 4 & Capoeiras & São João Batista e Santa Luzia \\
\hline 5 & Catedral & Nossa Senhora do Desterro e Santa Catarina \\
\hline 6 & Colégio Catarinense & Santa Catarina de Alexandria \\
\hline 7 & Coloninha & Santo Antônio e Santa Maria Goretti \\
\hline 8 & Coqueiros & Nossa Senhora do Carmo \\
\hline 9 & Estreito & Nossa Senhora de Fátima e Santa Teresinha do Menino Jesus \\
\hline 10 & Ingleses & Sagrado Coração de Jesus \\
\hline 11 & Jardim Atlântico & São José e Santa Rita de Cássia \\
\hline 12 & Lagoa da Conceição & Nossa Senhora da Imaculada Conceição da Lagoa \\
\hline 13 & Monte Verde & São Francisco Xavier \\
\hline 14 & Prainha & Santa Teresinha do Menino Jesus \\
\hline 15 & Ribeirão da Ilha & Nossa Senhora da Lapa \\
\hline 16 & Saco dos Limões & Nossa Senhora da Boa Viagem \\
\hline 17 & Santo Antônio & Santo Antônio \\
\hline 18 & Trindade & Santíssima Trindade \\
\hline
\end{tabular}

Fonte: Arquidiocese de Florianópolis - www.arquifln.org.br

\section{2 - Caracterização da Amostra}

O estudo foi desenvolvido na Paróquia Nossa Senhora da Lapa no Ribeirão da Ilha, que representa $5,5 \%$ do universo de dezoito paróquias do município de Florianopólis. Para desenvolver o estudo foram distribuídos questionários às dezoito comunidades integrantes da Paróquia Nossa Senhora da Lapa, relacionadas na Tabela 3. O critério para seleção da amostra foi a acessibilidade dos dados.

Os questionários foram estruturados nos seguintes blocos de informações:

a) Caracterização da Comunidade;

b) Caracterização da Estrutura de Trabalho;

c) Caracterização dos Procedimentos de Trabalho.

Esta pesquisa pode servir de parâmetro para outros estudos que venham a examinar práticas de controle interno em organizações religiosas, inclusive de outras crenças. $\mathrm{O}$ trabalho limita-se às declarações apresentadas nos questionários. Não foram realizados exames documentais, inspeções físicas ou outras técnicas utilizadas em auditoria.

Soares, L. L.; Vicente, E. F. R.; Lunkes, R. J. 
Tabela 3 - Comunidade da Paróquia Nossa Senhora da Lapa no Ribeirão da Ilha - Florianópolis

\begin{tabular}{|c|c|c|c|}
\hline Comunidade & Padroeiro(a) & Localidade & Criação \\
\hline 1 & São João Batista & Costeira da Barra do Sul & \\
\hline 2 & Santa Rita de Cássia & Pedregal & \\
\hline 3 & Nossa Senhora de Fátima & Costa de Dentro & \\
\hline 4 & Sossa Sra. Aparecida e São Cristóvão & Areias / M. das Pedras & \\
\hline 5 & Santa Cruz & Caieira da Barra do Sul & \\
\hline 6 & Som Jesus dos Pescadores & Tapera da Barra do Sul & \\
\hline 7 & São João Maria Vianney & Fazenda do Rio Tavares & \\
\hline 8 & Nossa Senhora de Lourdes & Sertão & \\
\hline 9 & Nossa Senhora da Lapa & Barro Vermelho & 1776 \\
\hline 10 & Sossa Senhora de Fátima e São Lucas & Tapera da Base & 1777 \\
\hline 11 & Sant'Ana e São Joaquim & Armação & 1777 \\
\hline 12 & Nossa Senhora da Lapa (Matriz) & Ribeirão da Ilha & 1809 \\
\hline 13 & São Sebastião & Campeche & 1840 \\
\hline 14 & São Pedro & Pântano do Sul & 1871 \\
\hline 15 & Santo Estevão & Alto Ribeirão & 1926 \\
\hline 16 & São José & Costeira do Ribeirão & 1953 \\
\hline 17 & Castanheiras & 2003 \\
\hline 18 & Nossa Senhora do Sagrado Coração & & \\
\hline
\end{tabular}

Fonte: Arquidiocese de Florianópolis - www.arquifln.org.br

\section{4 - Caracterização do Estudo}

\section{1 - Caracterização Organizacional da Instituição}

A Diocese de Florianópolis foi criada em 19 de março de 1908 pelo Papa Pio X com o mesmo nome, sendo naquela data a Matriz de Nossa Senhora do Desterro elevada a Catedral.

A 17 de janeiro de 1927 o Bispado de Florianópolis foi elevado a Arcebispado, deixando de ser sufragâneo (bispo dependente do Arcebispo) de Porto Alegre. Criaram-se as Dioceses de Lages e Joinville. Com este desmembramento, o território do antigo Bispado ficou reduzido a $20.514 \mathrm{Km}^{2}$. Em 1908 tornou-se uma igreja diocesana. Atualmente existem dez Dioceses: Florianópolis (1908), Joinville (1927), Lages (1927), Tubarão (1954), Chapecó (1958), Caçador (1968), Rio do Sul (1968), Joaçaba (1975), Criciúma (1998) e Blumenau (2000).

A arquidiocese de Florianópolis abrange 30 Municípios totalizando a superfície de $7.862,1 \mathrm{~km}^{2}$, com a população, segundo dados do IBGE 2008, de 1.462.906 habitantes e densidade demográfica de $173,91 \mathrm{hab} / \mathrm{km}^{2}$.

Administrativamente, a arquidiocese compreende 8 Comarcas Pastorais, 67 Paróquias e similares, 501 Capelas, 7 Santuários e 4 Seminários. A representação de sua estrutura hierárquica é representada na Figura 2.

\section{2 - Caracterização Regimental dos Conselhos e Assembléias de Pastoral}

A organização e funcionamento das paróquias e comunidades estão normatizados na forma de regimentos. Esses regimentos existem há longa data, mas em 2005 foram revistos e, após submissão e aprovação da Assembléia Arquidiocesana e do Conselho Arquidiocesano de Pastoral, foram autorizados pelo arcebispo de Florianópolis em 02 de fevereiro de 2006.

Pelo organograma apresentado na Figura 2, constata-se a constituição de dois tipos de conselhos: o Conselho Pastoral Paroquial (CPP) e, nas capelas, o Conselho Pastoral da Comunidade (CPC). 
Figura 2 - Representação da Estrutura Organizacional da Arquidiocese de Florianópolis

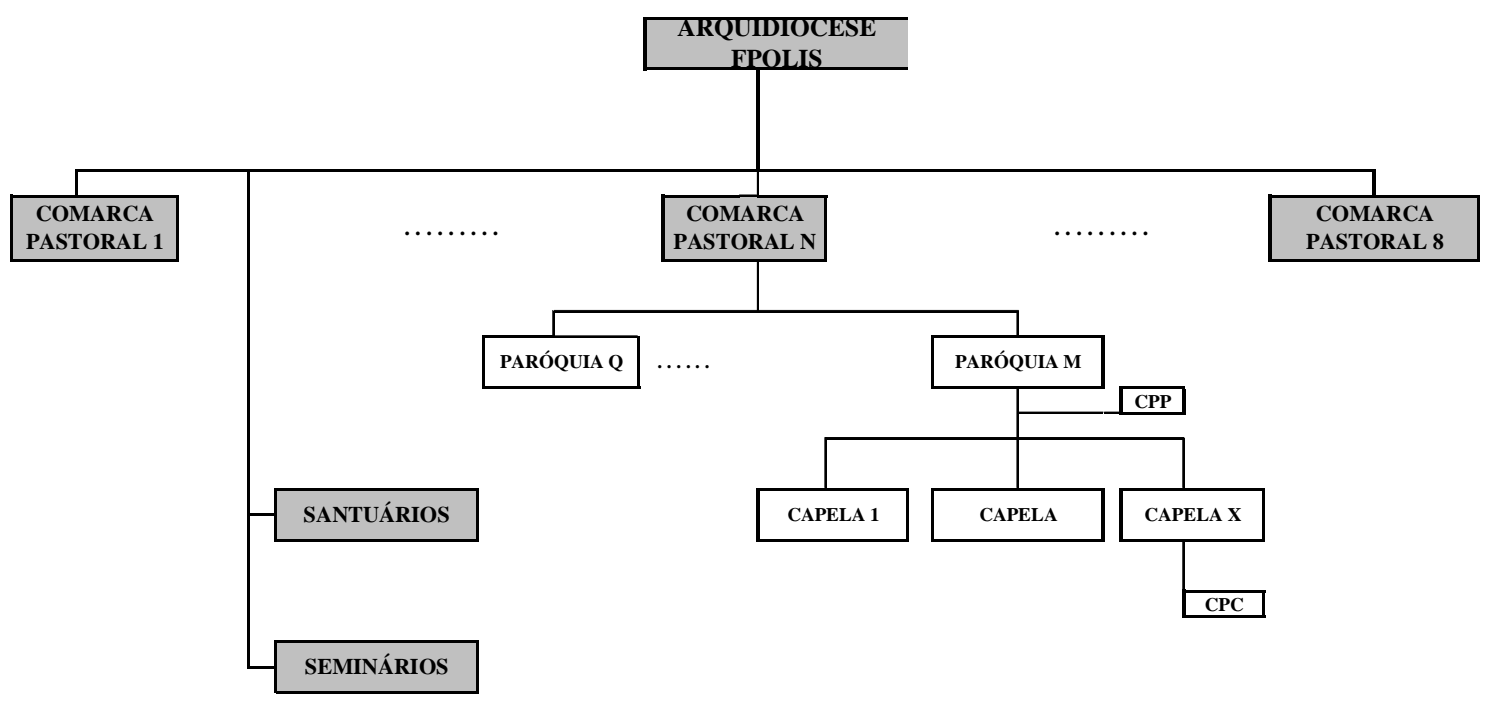

Fonte: Construção dos autores a partir do Regimento Interno dos Conselhos e Assembléias de Pastoral

O CPP assessora o Pároco na condução das atividades nas comunidades que integram a paróquia. Ele é formado pelos Coordenadores e Administradores Econômicos de cada capela-membro da paróquia.

É o CPC que dirige as atividades de uma comunidade, que desempenha atividades representativas e executivas. O regimento estabelece que o CPC seja constituído por:
a) o pároco e os vigários pastorais;
b) os diáconos permanentes da comunidade;
c) um representante dos institutos de vida consagrada;
d) o coordenador de cada ministério;
e) o coordenador de cada pastoral existente na comunidade;
f) o coordenador de cada movimento, associação e serviço;
g) o administrador econômico (tesoureiro);
h) outros que forem escolhidos pelo $C P C$, de acordo com a necessidade.

São objetivos do CPC, previstos no regimento:

1. articular, planejar, coordenar, e avaliar a caminhada pastoral na comunidade local, promovendo ação pastoral de conjunto;

2. despertar a consciência de uma igreja ministerial, incentivando as diversas vocações, para os ministérios ordenados, a vida consagrada, os ministérios leigos e as lideranças pastorais;

3. descobrir e incentivar novas modalidades de ação pastoral;

4. estudar e promover a captação de recursos financeiros e decidir sobre sua melhor aplicação de acordo com o espírito cristão;

5. organizar o dízimo como fonte principal da manutenção da pastoral. A coordenação do CPC será constituída por:

1. residente;

2. coordenador;

3. vice-coordenador;

4. $1^{\circ}$ secretário;

5. $2^{\circ}$ secretário;

6. administrador econômico (tesoureiro).

A Presidência do CPC será exercida pelo pároco e o coordenador, que são eleitos por votação secreta ou por aclamação. O coordenador, juntamente com o presidente, indicará o $1^{\circ}$ e $2^{\circ}$ secretários referendados pelos demais membros do CPC. $\underline{\mathrm{O} \text { administrador econômico será }}$ indicado pelo pároco e aprovado pelo CPC. Registra-se que o administrador econômico, além Soares, L. L.; Vicente, E. F. R.; Lunkes, R. J. 
de ser detentor da confiança da comunidade, necessita da indicação de nome pelo pároco, constituindo-se em uma espécie de "cargo de confiança".

A competência regimental do administrador econômico, segundo o art. 13, é constituir uma equipe de no mínimo três pessoas, aprovada pelo CPC, para:

1. Zelar pela conservação, reforma e ampliação dos bens e imóveis da comunidade;

2. Conduzir a rotina administrativa da comunidade;

3. Organizar as rendas da comunidade;

4. Apresentar mensalmente ao CPC prestação de contas;

5. Colaborar na organização da pastoral do dízimo;

6. Organizar as festas da comunidade juntamente com o CPC;

7. Apresentar ao CPC o orçamento anual;

8. Providenciar os pagamentos de rotina e os demais, aprovados pelo CPC;

9. Manter em ordem os livros contábeis;

10. Arquivar notas fiscais e recibos dos pagamentos efetuados;

11. Apresentar ao CPC projeto de previsão orçamentária das receitas e despesas (df Código de Direito Canônico-CDC, Cân 1287);

12. Apresentar ao CPC e à comunidade os balancetes de festas, promoções, aluguéis e do dízimo (cf CDC, Cân 1287);

13. Obedecer às normas de contabilidade e sujeitar-se às regras de controle e fiscalização financeira correspondentes;

14. Cumprir as obrigações sociais, conforme determina a lei.

$\S 1^{o}-O$ administrador econômico e o pároco agirão conjuntamente nas seguintes atividades financeiras: abrir e movimentar contas bancárias; sacar e transferir valores por meio eletrônico, emitir cheques, usar cartão eletrônico, depositar, retirar talão de cheques e extratos de conta corrente e fazer aplicações no sistema bancário.

$\S 2^{\circ}-O$ administrador econômico é membro do Conselho Paroquial de Pastoral.

Além de outras atribuições, compete aos membros do CPC "apreciar e aprovar os balanços financeiros".

O Regimento do CPC estabelece o seguinte para assuntos administrativos e econômicos:

"Art 15 - Conhecendo os interesses e a real situação da comunidade, compete ao CPC estudar o melhor uso dos imóveis e outros bens materiais da comunidade.

Parágrafo Único - Os membros do CPC devem ter consciência de que a economia e os recursos materiais devem estar prioritariamente a serviço da ação pastoral.

Art. 16 - Cabe ao CPC conscientizar a comunidade para a pastoral do dízimo, como fonte prioritária para a manutenção das obras da comunidade, para a promoção e sustentação das atividades pastorais e para a promoção social de pessoas empobrecidas.

Art. 17 - Todos os integrantes do CPC assumirão iniciativas e promoções que tenham por finalidade angariar recursos financeiros elou materiais, necessários para a sustentação, a melhoria, o desenvolvimento ou a conservação do patrimônio da comunidade. O mesmo princípio vale para a aquisição de bens, imóveis ou não, especialmente para aquisição de terrenos para as comunidades em formação, além dos bens que sejam importantes ou até necessários para uma ação pastoral eficiente.

Art.18 - Toda a comunidade eclesial tem o dever de contribuir, mensal ou anualmente, para a caixa-comum da paróquia, tendo em vista o atendimento de suas despesas normais e necessárias, pois a paróquia, além de seus gastos, contribui com a arquidiocese mensalmente. Os autores esclarecem que os valores das contribuições são estipulados pelo CPP de cada capela, face à realidade de cada comunidade. Os valores que excedem as contribuições regimentais permanecem na capela à disposição da comunidade.

Art. 19 - O CPC cuidará para que sejam feitas na comunidade as coletas anuais pré-determinadas:

1. para a igreja universal: Lugares Santos (Sexta-feira Santa); Óbolo de São Pedro (na festa de São Pedro e São Paulo); Missões ( $3^{\circ}$ Domingo de outubro);

2. para a igreja no Brasil: Coleta da Soliedariedade (Domingo de Ramos) e Campanha da Evangelização ( $3^{\circ}$ Domingo do Advento).

Art. 20 - A nomeação dos membros da coordenação do CPC será feita pelo arcebispo metropolitano, através de provisão.

Art. 22 - A destituição de algum membro do CPC só poderá ser feita com a anuência da autoridade arquidiocesana.

Controles Internos em Pequenas Comunidades Católicas de Florianópolis 
Art 23 - O mandato do CPC será de dois anos.

Parágrafo Único: Os membros do CPC poderão ser reconduzidos por um segundo período para a mesma função.

\section{5 - APRESENTAÇÃO E ANÁLISE DOS DADOS}

O questionário para a coleta de dados foi entregue para as oito comunidades presentes na reunião do mês de setembro do CPP - Conselho Pastoral Paroquial da paróquia Nossa Senhora da Lapa. Essa reunião é realizada a cada mês contando com a presença de todos os coordenadores e/ou tesoureiros dos CPCs das capelas da paróquia para discussão e decisão de assuntos em nível paroquial. Desta forma, os questionários foram entregues a $44 \%$ das comunidades membros e foram respondidos cinco questionários, representando $62 \%$ das capelas que receberam o questionário.

\section{1 - Caracterização da Comunidade}

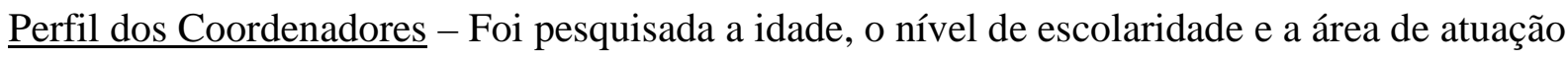
profissional dos administradores econômicos (tesoureiros)

Tabela 4 - Perfil etário, educacional e profissional dos coordenadores

\begin{tabular}{|c|c|c|c|c|}
\hline Comunidade & Nome & Idade & Escolaridade & Atuação \\
\hline A & Comunidade N Sra Fátima e S Lucas & 40 & Superior & Professor \\
\hline B & Comunidade Sta Cruz e N Sra Fátima & 40 & Ensino Médio & Marcenaria \\
\hline C & Bom Jesus de Iguape & 42 & Ensino Fundamental & Lixador de Tacos \\
\hline D & Capela São João Batista & 28 & Ens. Técnico Pós Médio & Eletrotécnica \\
\hline E & Capela N Sra Aparecida e São Cristóvão & 51 & Superior & Economista \\
\hline
\end{tabular}

Fonte: Questionários respondidos

Quanto ao perfil dos responsáveis pela arrecadação e aplicação dos recursos de cada comunidade, verifica-se que estão na faixa etária acima de 40 anos, o nível de escolaridade situa-se entre nível médio e nível superior. Evidencia-se que a formação acadêmica e/ou atuação profissional é variada e não há predominância de pessoas com formação contábil e/ou experiência financeira. Esse perfil heterogêneo pode ser devido à atividade ser exercida em caráter voluntário não remunerado, sem despertar o interesse de pessoas com formação acadêmica ou profissional mais compatível com as funções administrativas e financeiras desempenhadas em uma tesouraria.

\begin{tabular}{|c|c|c|c|c|}
\hline \multicolumn{2}{|c|}{ Figura 3 - Faixa etária dos coordenadores } & \multicolumn{3}{|c|}{ Figura 4 - Escolaridade dos coordenadores } \\
\hline \multicolumn{2}{|l|}{ Escolaridade } & \multirow[b]{2}{*}{$\begin{array}{c}\text { Acima de } 50 \\
\text { anos } \\
20 \% \\
\text { Até } 50 \text { anos } \\
20 \%\end{array}$} & \multicolumn{2}{|c|}{ Faixa Etária } \\
\hline$\underbrace{\substack{\text { Ensino } \\
\text { Superior }}}_{\substack{\text { Ensino } \\
\text { Ténico Pós } \\
\text { Médio } \\
20 \%}}$ & $\begin{array}{l}\text { DEnsino Fundamental } \\
\text { aEnsino Médlo } \\
\text { QEnsino Técnico Pós } \\
\text { Médio } \\
\text { aSuperior }\end{array}$ & & $\begin{array}{l}\text { Ate } 30 \text { anos } \\
20 \% \\
\text { Até } 40 \text { anos } \\
40 \%\end{array}$ & $\begin{array}{l}\text { पAlé } 30 \text { anos } \\
\text { aAle } 40 \text { anos } \\
\text { पAle } 50 \text { anos } \\
\text { DAcima de } 50 \text { anos }\end{array}$ \\
\hline Fonte: Questionários respondidos & & Fonte: Questiol & respondi & \\
\hline
\end{tabular}

Atividades Desenvolvidas - As comunidades desenvolvem atividades eminentemente religiosas para a manutenção e divulgação da doutrina cristã, mas também desenvolvem

Soares, L. L.; Vicente, E. F. R.; Lunkes, R. J. 
atividades em benefício da comunidade em geral, como atividades de integração de jovens e/ou idosos e campanhas de arrecadação para os necessitados.

Tabela 5 - Caracterização das atividades religiosas e leigas desenvolvidas nas comunidades

\begin{tabular}{|c|c|c|c|c|c|c|}
\hline \multicolumn{4}{|c|}{ Atividades de promoção religiosa } & \multicolumn{3}{|c|}{ Outras atividades em benefício da comunidade } \\
\hline Comunidade & Missas & $\begin{array}{c}\text { Cursos } \\
\text { preparatório } \\
\mathbf{s}\end{array}$ & $\begin{array}{c}\text { Grupos } \\
\text { de } \\
\text { oração }\end{array}$ & $\begin{array}{c}\text { Grupo de } \\
\text { jovens e/ou } \\
\text { de idosos }\end{array}$ & $\begin{array}{c}\text { Apoio a grupos de } \\
\text { ajuda a } \\
\text { dependentes } \\
\text { alcoólicos } \\
\end{array}$ & $\begin{array}{c}\text { Atividades } \\
\text { assistenciais } \\
\text { eventuais }\end{array}$ \\
\hline A & uma semanal & $\begin{array}{l}\text { batismo } \\
\text { eucaristia } \\
\text { crisma }\end{array}$ & $\operatorname{sim}$ & $\operatorname{sim}$ & $\operatorname{sim}$ & não \\
\hline $\mathrm{B}$ & uma semanal & eucaristia & $\operatorname{sim}$ & $\operatorname{sim}$ & $\operatorname{sim}$ & $\operatorname{sim}$ \\
\hline $\mathrm{C}$ & uma semanal & eucaristia & não & não & não & não \\
\hline $\mathrm{D}$ & $4^{\circ}$ domingo do mês & $\begin{array}{c}\text { eucaristia } \\
\text { crisma } \\
\text { matrimônio }\end{array}$ & não & jovens & não & $\operatorname{sim}$ \\
\hline $\mathrm{E}$ & $\begin{array}{c}\text { uma semanal e toda } \\
\text { primeira sexta-feira } \\
\text { do mês }\end{array}$ & $\begin{array}{l}\text { batismo } \\
\text { eucaristia } \\
\text { crisma }\end{array}$ & não & não & não & $\begin{array}{c}\text { repasse mensal } \\
\text { para a ONG } \\
\text { ação social }\end{array}$ \\
\hline
\end{tabular}

Fonte: Questionários respondidos

Evidencia-se que todas comunidades prestam apoio à promoção de atividades religiosas, contando com uma missa semanal, e de cursos de preparação para os sacramentos católicos (Batismo, Primeira Eucaristia, Crisma e Casamento). A promoção de grupos de oração ocorrem em $40 \%$ das comunidades. Todas as comunidades também cedem seus espaços para a promoção de atividades de assistência social em benefício de grupos de jovens e idosos e realizam eventuais campanhas de arrecadação de donativos.

\section{2 - Caracterização da Estrutura de Trabalho}

Foram realizados questionamentos quanto às condições materiais para a execução das atividades, como espaço físico para o desenvolvimento do trabalho e para o arquivamento dos documentos, equipamentos e softwares disponíveis, bem como a disponibilidade de recursos humanos para auxiliar nas atividades.

Quanto à estrutura de trabalho, evidencia-se que as comunidades não dispõem de um ambiente de trabalho, equipado com computador, reservado exclusivamente para as atividades administrativas decorrentes das práticas de uma tesouraria. Tais atividades normalmente são desenvolvidas na residência do tesoureiro com a utilização de seus equipamentos e às vezes até com a ajuda de terceiros de boa vontade.

Aqueles que se utlizam de computadores para controlar os recursos não dispõem de softwares específicos e o fazem através de planilhas eletrônicas.

Evidencia-se também que o coordenador e o tesoureiro em algumas comunidades executam suas atribuições sem auxílio de outros participantes, devido à indisponibilidade de voluntários. 
Tabela 6 - Recursos disponíveis para as atividades dos coordenadores

\begin{tabular}{|c|c|c|c|c|c|}
\hline \multirow[t]{2}{*}{ Comunidade } & \multicolumn{2}{|c|}{ Espaço físico disponível } & \multicolumn{2}{|c|}{ Recursos de informática } & \multirow{2}{*}{$\begin{array}{c}\begin{array}{c}\text { Recursos } \\
\text { humanos }\end{array} \\
\text { Auxílio ao } \\
\text { coordenador ou } \\
\text { tesoureiro }\end{array}$} \\
\hline & $\begin{array}{c}\text { Exclusivo para } \\
\text { trabalhos } \\
\text { financeiros }\end{array}$ & $\begin{array}{l}\text { Arquivamento de } \\
\text { documentos } \\
\text { contábeis }\end{array}$ & Computador & Softwares & \\
\hline $\mathrm{A}$ & não & $\begin{array}{l}\text { residência do } \\
\text { tesoureiro e } \\
\text { igreja matriz }\end{array}$ & $\begin{array}{l}\text { particular, de } \\
\text { terceiros }\end{array}$ & $\operatorname{sim}$ & sempre \\
\hline B & não & $\begin{array}{l}\text { residência do } \\
\text { tesoureiro e } \\
\text { igreja matriz }\end{array}$ & $\begin{array}{l}\text { particular, de } \\
\text { membro do } \\
\text { CPC }\end{array}$ & não respondeu & $\begin{array}{c}\text { eventualmente, } \\
\text { pois há poucas } \\
\text { pessoas } \\
\text { disponíveis }\end{array}$ \\
\hline $\mathrm{C}$ & não & igreja matriz & não & não & $\begin{array}{c}\text { eventualmente, } \\
\text { pois há poucas } \\
\text { pessoas } \\
\text { disponíveis }\end{array}$ \\
\hline $\mathrm{D}$ & não & igreja matriz & $\begin{array}{l}\text { particular, de } \\
\text { membro do } \\
\text { CPC }\end{array}$ & $\begin{array}{c}\text { planilhas do tipo } \\
\text { excel }\end{array}$ & nunca \\
\hline $\mathrm{E}$ & não & $\begin{array}{l}\text { cúria (original) e } \\
\text { coordenador } \\
\text { (cópia) }\end{array}$ & $\begin{array}{l}\text { particular, de } \\
\text { membro do } \\
\text { CPC }\end{array}$ & $\begin{array}{c}\text { planilhas do tipo } \\
\text { excel }\end{array}$ & $\begin{array}{c}\text { na maioria das } \\
\text { vezes em que é } \\
\text { necessário }\end{array}$ \\
\hline
\end{tabular}

Fonte: Questionários respondidos

\section{3 - Caracterização dos Procedimentos de Trabalho}

Fontes de Receitas

Foram perguntados os quais os tipos de receitas da comunidade.

Tabela 7 -Detalhamento das receitas auferidas pelas comunidades

\begin{tabular}{|c|c|c|c|c|c|c|}
\hline Comunidade & Dízimo mensal & $\begin{array}{c}\text { Coletas nas } \\
\text { missas }\end{array}$ & $\begin{array}{c}\text { Doações } \\
\text { espontâneas }\end{array}$ & $\begin{array}{c}\text { Festas dos } \\
\text { padroeiros }\end{array}$ & $\begin{array}{c}\text { Outros } \\
\text { eventos }\end{array}$ & $\begin{array}{c}\text { Aluguéis de } \\
\text { salão e igreja }\end{array}$ \\
\hline A & $\operatorname{sim}$ & $\operatorname{sim}$ & não & duas anuais & & - \\
\hline B & $\operatorname{sim}$ & $\operatorname{sim}$ & $\operatorname{sim}$ & uma anual & & salão \\
\hline C & $\operatorname{sim}$ & $\operatorname{sim}$ & $\operatorname{sim}$ & duas anuais & & não \\
\hline D & $\operatorname{sim}$ & $\operatorname{sim}$ & $\operatorname{sim}$ & duas anuais & $\begin{array}{c}\text { bingos, } \\
\text { almoços }\end{array}$ & não \\
\hline E & $\operatorname{sim}$ & $\operatorname{sim}$ & $\operatorname{sim}$ & não & rifas & não \\
\hline
\end{tabular}

Fonte: Questionários respondidos

Observa-se que todas as comunidades, excetuando-se a 'E', complementam as receitas religiosas (dízimos, coletas em missas e doações espontâneas) com atividades organizadas para arrecadação de fundos que são as festas em homenagem aos padroeiros da comunidade, promovidas uma ou duas vezes ao ano.

A comunidade ' $\mathrm{B}$ ' também aufere receitas com aluguel do salão paroquial para festas particulares que se coadunem com os objetivos cristãos. Evidencia-se, pela promoção de eventos e locação de espaço, iniciativas necessárias em busca de mais recursos,

\section{Controles das receitas}

Foi questionado como as coletas das missas e contribuições dos dizimistas são recebidas e contadas e quem faz o registro dessas receitas.

As coletas são recolhidas, normalmente, em cestas abertas ficam, contudo, à vista (vigilância) dos demais membros da comunidade ou do encarregado pelo seu recolhimento. A contagem das coletas e do dízimo recebido é realizada por duas ou mais pessoas, sendo às

Soares, L. L.; Vicente, E. F. R.; Lunkes, R. J. 
vezes com a participação do tesoureiro. A equipe do dízimo dispõe de um caderno, onde são registrados valores recebidos em cada celebração. Os valores são entregues ao tesoureiro para os respectivos pagamentos, depósitos e providências para a elaboração dos demonstrativos mensais de receitas e despesas. Ao tesoureiro compete apresentar mensalmente o demonstrativo de todas as receitas auferidas no mês.

Tabela 8 -Procedimentos de controle no recolhimento das receitas

\begin{tabular}{|c|c|c|c|c|}
\hline Comunidade & $\begin{array}{c}\text { Realização das } \\
\text { coletas nas missas }\end{array}$ & Contagem das coletas & $\begin{array}{c}\text { Recolhimento do } \\
\text { dízimo }\end{array}$ & Registro das receitas \\
\hline $\mathrm{A}$ & $\begin{array}{l}\text { cestas/caixas } \\
\text { abertas }\end{array}$ & $\begin{array}{c}\text { duas pessoas } \\
\text { (fiscais do CPC e } \\
\text { coordenador/secretário) }\end{array}$ & coletas das missas & $\begin{array}{l}\text { tesoureiro - todas as receitas } \\
\text { pastoral do dízimo - dízimo }\end{array}$ \\
\hline B & $\begin{array}{l}\text { cestas/caixas } \\
\text { abertas }\end{array}$ & $\begin{array}{c}\text { duas pessoas } \\
\text { (tesoureiro e auxiliar) }\end{array}$ & coletas das missas & $\begin{array}{l}\text { tesoureiro - todas as receitas } \\
\text { pastoral do dízimo - dízimo }\end{array}$ \\
\hline $\mathrm{C}$ & $\begin{array}{c}\text { cestas/caixas } \\
\text { abertas }\end{array}$ & $\begin{array}{c}\text { duas pessoas } \\
\text { (tesoureiro e coordenador) }\end{array}$ & $\begin{array}{c}\text { carnê de } \\
\text { contribuição }\end{array}$ & $\begin{array}{l}\text { tesoureiro - todas as receitas } \\
\text { pastoral do dízimo - dízimo }\end{array}$ \\
\hline $\mathrm{D}$ & $\begin{array}{l}\text { cestas/caixas } \\
\text { abertas }\end{array}$ & $\begin{array}{c}\text { mais de duas pessoas } \\
\text { (tesoureiro e coordenador } \\
\text {, outros membros do CPC, } \\
\text { catequistas) }\end{array}$ & coletas das missas & $\begin{array}{l}\text { tesoureiro - todas as receitas } \\
\text { pastoral do dízimo - dízimo }\end{array}$ \\
\hline $\mathrm{E}$ & $\begin{array}{l}\text { caixas/baús } \\
\text { fechados }\end{array}$ & $\begin{array}{l}\text { mais de duas pessoas } \\
\text { (equipe do dízimo) }\end{array}$ & coletas das missas & $\begin{array}{c}\text { coleta - pessoas do CPC } \\
\text { pastoral do dízimo - dízimo } \\
\text { doações espontâneas - } \\
\text { pessoas do CPC }\end{array}$ \\
\hline
\end{tabular}

Fonte: Questionários respondidos

Controles das despesas - Aplicação dos recursos financeiros

Foi perguntado onde permanecem os recursos da comunidade. Verifica-se que todas as comunidades dispõem de conta bancária e aplicações caderneta de poupança ou fundo de renda fixa. Uma pequena parcela permanece em caixa para eventuais pagamentos.

Tabela 9 -Aplicação das receitas arrecadadas

\begin{tabular}{|c|c|c|c|c|c|}
\hline Comunidade & $\begin{array}{c}\text { Dinheiro disponível } \\
\text { em caixa }\end{array}$ & Conta bancária & $\begin{array}{c}\text { Caderneta de } \\
\text { poupança }\end{array}$ & Renda fixa & Renda variável \\
\hline A & às vezes & $\operatorname{sim}$ & não & não & não \\
\hline B & sempre & $\operatorname{sim}$ & não & $\operatorname{sim}$ & não \\
\hline C & sempre & $\operatorname{sim}$ & $\operatorname{sim}$ & não & não \\
\hline D & sempre & $\operatorname{sim}$ & não & não & não \\
\hline E & sempre & $\operatorname{sim}$ & não & sim & não \\
\hline
\end{tabular}

Fonte: Questionários respondidos

\section{Execução das despesas}

Foi questionado quem executa as despesas em benefício da comunidade, quais os documentos aceitos para comprovação das despesas e quando ocorre a prestação de contas à comunidade.

As emissão de cheques necessita da assinatura de pelo menos dois membros do CPC, a exemplo do que ocorre nas demais pessoas jurídicas. Observa-se que somente pessoas autorizadas podem realizar despesas com os recursos da comunidade.

O tesoureiro efetua contagem das coletas e recebimento das demais receitas (dízimos, doações e festas), participa da realização das despesas e procede o registro das entradas e saídas dos recursos. Essa situação revela certa ausência de segregação de funções, decorrente da necessidade de uma atuação mais flexível, uma vez que as equipes são reduzidas em quantidade de participantes, bem como em tempo disponível, uma vez que o trabalho é voluntário e não remunerado, não havendo dedicação exclusiva dos participantes. As 
comunidades não protegem o seu patrimônio com a contratação de seguros.

Tabela 10 -Procedimentos de controle na execução das despesas

\begin{tabular}{|c|c|c|c|c|c|}
\hline Comunidade & $\begin{array}{l}\text { Assinatura } \\
\text { de cheques }\end{array}$ & $\begin{array}{l}\text { Realização de } \\
\text { despesas }\end{array}$ & $\begin{array}{c}\text { Documentos } \\
\text { comprobatórios de despesas }\end{array}$ & $\begin{array}{l}\text { Pagamento de } \\
\text { seguro contra } \\
\text { roubo/incêndi } \\
\text { o }\end{array}$ & $\begin{array}{l}\text { Prestação de } \\
\text { contas }\end{array}$ \\
\hline $\mathrm{A}$ & $\begin{array}{c}\text { duas } \\
\text { pessoas }\end{array}$ & $\begin{array}{l}\text { coordenador ou } \\
\text { tesoureiro }\end{array}$ & notas fiscais & não & $\begin{array}{l}\text { mensalmente à } \\
\text { comunidade e à } \\
\text { igreja matriz }\end{array}$ \\
\hline B & três pessoas & $\begin{array}{c}\text { só pessoas } \\
\text { autorizadas pelo } \\
\text { CPC }\end{array}$ & $\begin{array}{l}\text { notas fiscais e recibos com } \\
\text { identificação do recebedor }\end{array}$ & não & $\begin{array}{l}\text { mensalmente à } \\
\text { comunidade e à } \\
\text { igreja matriz }\end{array}$ \\
\hline $\mathrm{C}$ & $\begin{array}{c}\text { duas } \\
\text { pessoas }\end{array}$ & $\begin{array}{c}\text { só pessoas } \\
\text { autorizadas pelo } \\
\text { CPC } \\
\end{array}$ & $\begin{array}{l}\text { notas fiscais e } \\
\text { cupons fiscais }\end{array}$ & não & $\begin{array}{l}\text { mensalmente à } \\
\text { comunidade }\end{array}$ \\
\hline $\mathrm{D}$ & $\begin{array}{c}\text { duas } \\
\text { pessoas }\end{array}$ & $\begin{array}{c}\text { só pessoas } \\
\text { autorizadas pelo } \\
\text { CPC }\end{array}$ & $\begin{array}{c}\text { notas fiscais, } \\
\text { cupons fiscais e recibos com } \\
\text { identificação do recebedor }\end{array}$ & não & $\begin{array}{c}\text { após grandes } \\
\text { eventos e sem } \\
\text { periodicidade } \\
\text { definida }\end{array}$ \\
\hline$E$ & $\begin{array}{c}\text { duas } \\
\text { pessoas }\end{array}$ & $\begin{array}{l}\text { coordenador ou } \\
\text { tesoureiro }\end{array}$ & $\begin{array}{c}\text { notas fiscais, } \\
\text { cupons fiscais e recibos com } \\
\text { identificação do recebedor }\end{array}$ & não & $\begin{array}{l}\text { mensalmente à } \\
\text { comunidade }\end{array}$ \\
\hline
\end{tabular}

Fonte: Questionários respondidos

Relações de trabalho:

Foi questionado quais os tipos de serviços demandados pela comunidade para manter em funcionamento as atividades de cada capela. Além dos serviços de fornecimento de água e luz, são demandados serviços de limpeza, jardinagem e manutenção predial. Foi questionado também como são formalizadas as relações de trabalho e sua remuneração.

Tabela 11 -Remuneração e formalização dos serviços demandados

\begin{tabular}{|c|c|c|c|c|}
\hline Comunidade & $\begin{array}{c}\text { Serviços de } \\
\text { limpeza }\end{array}$ & $\begin{array}{c}\text { Serviços de } \\
\text { jardinagem }\end{array}$ & $\begin{array}{c}\text { Serviços de } \\
\text { manutenção predial }\end{array}$ & $\begin{array}{c}\text { Formalização de } \\
\text { contrato }\end{array}$ \\
\hline A & sem remuneração & sem remuneração & com remuneração & não \\
\hline B & sem remuneração & sem remuneração & sem remuneração & não \\
\hline C & $\begin{array}{c}\text { misto voluntário e } \\
\text { com remuneração }\end{array}$ & $\begin{array}{c}\text { misto voluntário e } \\
\text { com remuneração }\end{array}$ & $\begin{array}{c}\text { misto voluntário e com } \\
\text { remuneração }\end{array}$ & não \\
\hline D & sem remuneração & sem remuneração & sem remuneração & não \\
\hline E & sem remuneração & sem remuneração & $\begin{array}{c}\text { misto voluntário e com } \\
\text { remuneração }\end{array}$ & não \\
\hline
\end{tabular}

Fonte: Questionários respondidos

Observa-se que as atividades de serviço continuado não ligadas às atividades religiosas são realizadas num percentual de $80 \%$ de forma voluntária, ou seja, sem remuneração. As relações de trabalho para manutenção das instalações prediais ocorrem, geralmente, de forma remunerada.

Quanto à formalização dos contratos de trabalhos, seja para os serviços prestados de forma voluntária ou para os remunerados, constata-se que nenhuma comunidade formaliza as relações de trabalho, especificando os direitos e obrigações das partes. 


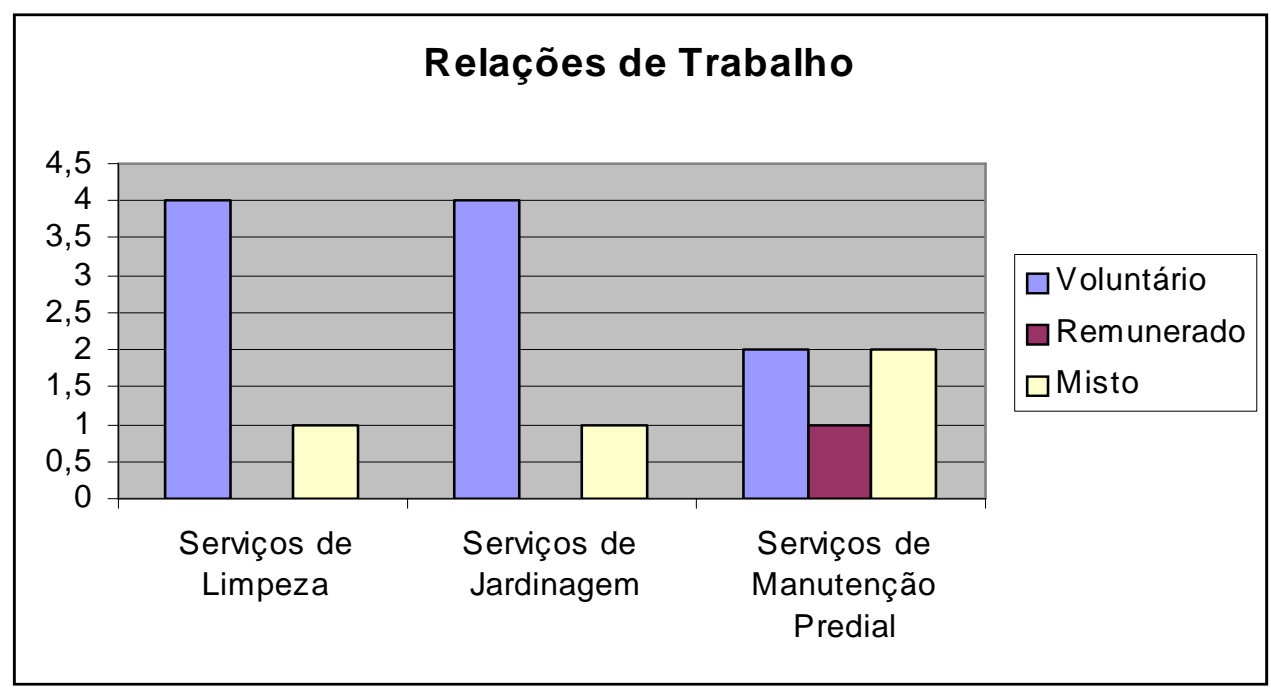

Figura 5 -Serviços continuados demandados e sua remuneração

Fonte: Questionários respondidos

Evidencia-se, neste caso, fragilidades para a entidade, devido a sua responsablidade como pesoa jurídica. Há necessidade de aperfeiçoamento nas práticas de contratação de serviços.

\section{6 - Conclusão}

A análise das informações levantadas junto às comunidades nos permite concluir que:

a) as pequenas comunidades católicas de Florianópolis estão estruturadas na forma de conselhos e há um Regimento que define a composição e as atribuições de cada membro do conselho;

b) as comunidades dispõem de conta bancária para depósito dos recursos arrecadados e efetuam aplicações em caderneta de poupança ou fundos de renda fixa que contam com garantias e liquidez. Observa-se o cumprimento do princípio da entidade, pois os recursos da comunidade são aplicados em nome da comunidade e somente uma pequena parcela permanece em caixa;

c) há apresentação de prestações de contas ao CPC, ao CPP e à comunidade em geral com regularidade, permitindo que se acompanhe a aplicação dos recursos, portanto as comunidades procuram atender aos preceitos da accountability;

d) o administrador econômico arrecada, aplica, registra as receitas e despesas gerando falta de segregação de funções, contudo as atividades de arrecadação, principalmente as contagens de coletas e recebimento de dízimos, sempre são realizadas por mais de uma pessoa;

e) a estrutura de trabalho apresenta carências. As comunidades não dispõem de espaço físico adequado nem de equipamentos e software para auxiliar nas atividades de controle das arrecadações e apresentação de demonstrativos de receitas e despesas para a comunidade e para os conselhos da comunidade e da paróquia.

A diocese deveria padronizar procedimentos, tendo em vista a heterogeneidade do perfil das equipes responsáveis pela gestão dos recursos financeiros. A utilização de um software único em todas as paróquias e adequado às características das comunidades, que são 
comuns, contribuiria para uma melhor gestão. Também seria importante ministrar treinamento às equipes no momento de sua transição, tal como ocorre nas empresas privadas.

Podemos afirmar que as pequenas comunidades católicas de Florianópolis dispõem de mecanismos de controle interno emanados da arquidiocese de Florianópolis através das normas estipuladas em regimentos, que toda a arrecadação é depositada em conta bancária da comunidade, que há controles sobre a arrecadação das receitas, sendo algumas receitas identificadas e que há controles sobre a realização de despesas. Observou-se a existência de níveis de autoridade e a segregação de responsabilidades. Identificaram-se fragilidades quanto a falta de recursos materiais (espaço físico e recursos de informática) e falta de pessoal voluntário, o que acarreta muitas vezes a acumulação de atividades, comprometendo a segregação de funções prevista regimentalmente.

O presente estudo, por adotar em sua metodologia a coleta de dados a partir de questionários com questões estruturadas, pode ser replicado em comunidades ou instituições de outras religiões/credos.

\section{Referências}

ABDUL-RAHMAN, Abdul Rahim, GODDARD, Andrew. Accountability verstehen: A study of accounting in state religious councils in Malaysia. Southampton, UK, University of Southampton. Discussion Papers in Accounting \& Finance. 2003. Disponível em < http://eprints.soton.ac.uk/35833/>

ALVES, Vanessa Olak, OLAK, Paulo Arnaldo, SLOMSKI Valmor, As publicações acadêmicas da pesquisa contábil no Brasil, no âmbito das organizações do terceiro setor. Revista de Educação e Pesquisa em Contabilidade, Vol. 2, No 1 (2008). Brasília/DF

BRASIL. Congresso Nacional. Constituição da República Federativa do Brasil de 1988. Disponível em <www.planalto.gov.br/ccivil_03/Constituicao/Constituiçao.htm> Acesso em 08/07/2009

BRASIL. Congresso Nacional. Lei $\mathbf{n}^{\mathbf{0}}$ 10.406, que instituiu o Código Civil em 10 de janeiro de 2002. Disponível em <www.planalto.gov.br/ccivil_03/LEIS/2002/L10406.htm> Acesso em 08/07/2009

CONSELHO FEDERAL DE CONTABILIDADE. NBC T 10.19 Aspectos Contábeis Entidades sem fim lucro. 20/04/2000. Disponível em <www.cfc.org.br $>$. Acesso em $10 / 10 / 2009$

FONFEDER, Robert, HOLTZMAN, Mark P, MACCARRONE, Eugene, Internal controls in the Talmud: The Jerusalem Temple. The Accounting Historians Journal, Academy of Accounting Historians, State of Alabama, United States. Junho de 2003

FRANÇA, Robério Dantas de. Sistemas de controle no terceiro setor: Um estudo exploratório das igrejas Batistas da grande João Pessoa. 2007. Dissertação de Mestrado Programa de Pós-graduação Muiltiinstitucional e Inter-regional em Ciências Contábeis da UNB, UFPB, UFPE e UFRN.

GARCIA, Gilberto. As Igrejas e as Obrigações Legais e Dízimo: Contribuição Voluntária do Fiel. Disponíveis em <www.direitonosso.com.br/> Acesso em 10/10/2009. 
GIL, Antonio Carlos. Metodologia do Ensino Superior. 3 ed. São Paulo: Atlas, 1997, p. 90 246.

LUNKES, Rogério João, SCHNORRENBERGER, Darci. Controladoria na Coordenação dos Sistemas de Gestão. São Paulo: Atlas. 2009

OLIVEIRA, Aristides da Rocha. A gestão estratégica no terceiro setor: estudo de caso numa organização eclesiástica. 2002. Dissertação de Mestrado. Escola Brasileira de Administração Pública e de empresas - EBAPE. Fundação Getúlio Vargas.

Regimento Interno dos Conselhos e Assembléias de Pastoral. Arquidiocese de Florianópolis. 2006. SC

SULAIMAN, Maliah, The Internal Control Procedures of Mosques in Malaysia. Revista Universo Contábil, Vol. 3, No 2 (2007)

YIN, Robert K. Estudo de caso: planejamento e métodos. 2 ed. Porto Alegre: Bookman, 2001.

WEST, Robert, ZECH, Charles. Internal Financial Controls in the U.S. Catholic Church. Journal of Forensic Accounting/Vol. IX (2008), pp. 129-156. 2008 R.T. Edwards, Inc.. U.S.A. 